\title{
A FROST HARDINESS STUDY OF SIX CONIFEROUS SPECIES ${ }^{1}$
}

\author{
By C. GLERUM, ${ }^{2}$ J. L. FARRAR ${ }^{3}$ and R. L. MCLURE
}

\section{ABSTRACT}

In the summer of 1963, the frost hardiness of six native coniferous species was tested. It was found that temperature and degree of frost damage were linearly related. The frost hardiness increased from the first week (Aug. 11) to the fifth week (Sept. 8) of testing. The most sensitive species were those which were growing most actively.

\section{INTRODUCTION}

Frosts cause considerable damage to forest trees annually throughout Canada. In 1963, for example, late spring frosts caused extensive damage to the new growth on a number of trees in parts of central and western Canada (Canada Department of Forestry, 1963). One way to reduce frost damage is to be familiar with the frost hardiness of our native tree species. Since little information on this topic is available, it was decided to conduct an experiment during the summer of 1963, in which seedlings in a nursery were subjected to artificial frosts.

It is generally accepted that late varieties, trees which start growth late in the spring, are less vulnerable to spring frosts than early varieties (Korstian, 1921; Baker, 1934; Day and Peace, 1934). The late varieties are less vulnerable by virtue of their dormancy, when frosts occur. The late varieties are not necessarily hardier than the earlier varieties when they are compared at a similar stage of development. Consequently, the developmental stage of the trees at the time of a frost should be taken into consideration. This has not always been done, accounting in part for the discrepancies found in the literature as to the relative hardiness of various species (Korstian, 1921; Baker, 1934; Hough, 1945; Pomerleau and Ray, 1957; Stoeckeler, 1965).

Differences of opinion concerning the degree of frost which causes damage during the summer also exist. For example, in Connecticut, Parker (1961) found that twigs of white pine and hemlock were resistant to about $18^{\circ} \mathrm{F}$., whereas in England, Day and Peace (1934) found that most conifers were resistant from $22^{\circ} \mathrm{F}$. to $27^{\circ} \mathrm{F}$.

\footnotetext{
${ }^{3}$ Contribution No. 65-17. Ontario Department of Lands and Forests, Maple, Ontaria Part of a thesis for the degree of M.Sc.F. at the University of Toronto.

- Research Forester, Ontario Department of Lands and Forests.

- Abitibi Professor of Forest Biology, Faculty of Forestry, University of Toronto.

- Research Assistant, Connaught Medical Research Laboratories, University of Toronka.
} 


\section{Materials AND METHOds}

The species and age-classes of the stock used were (1) 3-0 white pine, Pinus strobus, L. (Pw); (2) 3-0 red pine, P. resinosa Ait. ( $\mathrm{Pr}$ ); (3) 3-0 jack pine, $P$. banksiana, Lamb $(\mathrm{Pj})$; (4) 2-0 Eastern larch or tamarack, Larix laricina (Du Roi) K. Koch (Lt); (5) 3-0 white spruce, Picea glanca (Moench) Voss (Sw) and (6) 2-0 black spruce, P. mariana (Mill.) B.S.P. $\mathrm{Sb}$. The average height in inches was: white pine 6 ; red pine $61 / 2$; jack pine 8 ; larch 7 ; white spruce 7 and black spruce $4 \frac{1}{2}$.

The freezing tests were conducted during a five week period (Aug. 11-Sept. 15, 1963) at the Midhurst Forest Tree Nursery of the Ontario Department of Lands and Forests. All the tests were conducted outof-doors, on seedlings growing in nursery beds. Not all species were tested every week. The number of seedlings subjected to frost in each test varied, depending on the spacing of the seedlings in the nursery seedbeds. The average number of trees per test were: white pine 15; red pine 17; jack pine 44; larch 24; white spruce 16 and black spruce 117.

The stage of development of the species varied considerably at the time of testing. The red, white and jack pine and white spruce had completed their height growth, while most of the new growth of the larch and black spruce was still succulent and the terminal buds had not completed their development.

The freezing apparatus used is illustrated in Figs. 1 and 2 and is similar to the apparatus described by Paulsell and Lawrence (1963). The apparatus was made from an 18 inch diameter fibre drum which had a wall thickness of $3 / 16$ inches and was lined with one inch thick foam rubber insulation. Six thermometers with a range of $-40^{\circ} \mathrm{F}$. to $120^{\circ} \mathrm{F}$. were inserted through the walls of the lower compartment, as illustrated in Fig. 2 .

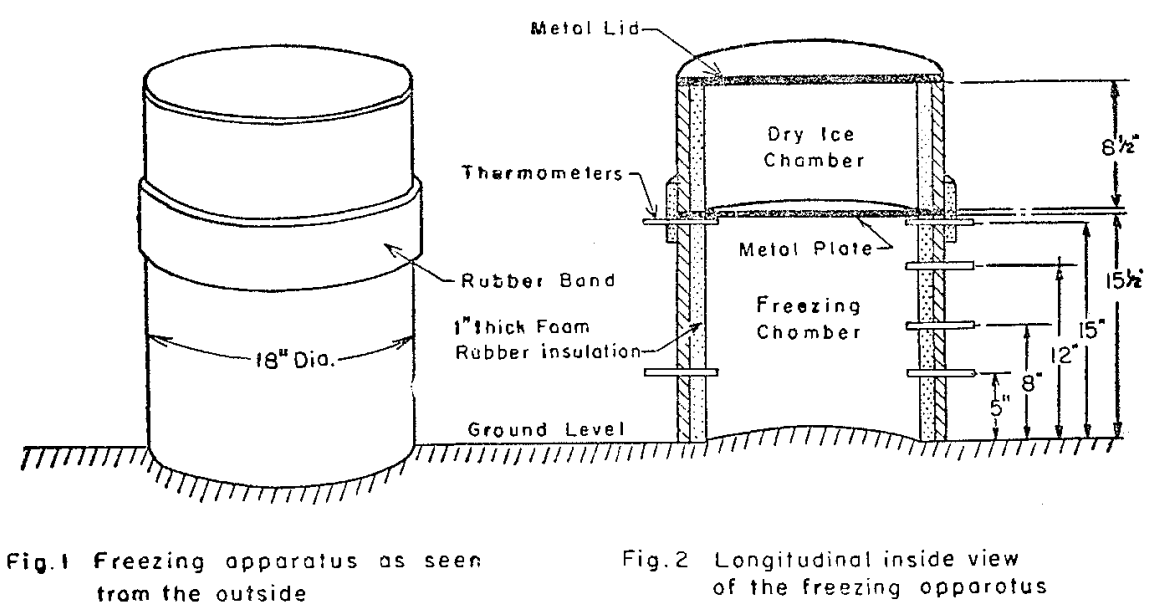


Solid carbon dioxide (dry ice) was used as the refrigerant. To measure temperatures near and around the trees, two iron-constantan thermocouples and one thermistor, the latter having an air-temperature probe, were used. All the temperature measuring devices used corresponded within 1 Fahrenheit degree.

As soon as dry ice was placed on the metal plate, the temperature within the freezing chamber decreased rapidly for about five minutes. After fifteen minutes the temperature remained fairly constant for one to two hours. Therefore, an unspecified amount of dry ice was used so that the temperature dropped to between $30^{\circ} \mathrm{F}$. and $35^{\circ} \mathrm{F}$. This temperature was maintained by adding more dry ice when required, for about one to one and one-half hours. Subsequently, dry ice was added to decrease the temperature to the temperature range desired (or as close as possible), which required about one hour. This temperature range was maintained for about one hour, by adding dry ice when required. Subsequently, dry ice was removed so that the air in the freezing chamber warmed up gradually.

Considerable differences in temperature occurred within the freezing chamber. The temperatures presented in the result were measured near the upper parts of the seedlings, where damage was likely to occur. After each test was completed, the trees in that test were allowed to recuperate for a period of one to four weeks. At the end of the recuperation period (Sept. 17 and 18) the frost damage on each tree was ocularly estimated, using the extent of browning of the needles and twigs as a criterion for damage. Only the above-ground portion of the trees was considered, and the damage was expressed as per cent of this portion. In conifers frost damage becomes evident within 3 days after the frost. The accompanying discolouration is easily recognized but hard to describe. In time, two to four weeks after the frost, this discolouration becomes various shades of brown.

In addition to the main experiment, some preliminary trials were carried out on forty 2-2-1 and eleven 2-2-2 white spruce from the nursery. These spruce were actively growing at the time of the frost.

\section{RESULTS}

The minimum temperature was obtained by averaging the highest and lowest temperature of the minimum temperature range. The per cent damage was obtained by dividing the sum of all the damage in the test (the damage was estimated for each tree) by the number of trees per test.

The relationship between per cent damage and minimum temperature was complicated by an unbalanced arrangement of date (in weeks) and species. This necessitated the use of elaborate multiple regression procedures to calculate values of per cent damage, which corresponded to the observed values at different temperatures and dates for the various species. The data were divided into five categories by week (from Aug. 11 to Sept. 15) and no assumption was made about the shape of the trend with date. Thus instead of a simple regression of per cent damage versus 
temperature, nine independent variables were added (5 for species; 4 for date, i.e. weeks) ( $\mathrm{Li}, 1964)$.

The analysis was carried out on the IBM 7094-II at the University of Toronto and statistical tests were made of the significance of the effects of the factors on per cent damage. ${ }^{5}$ The data were tested for curvature. The quadratic term of the regression of damage on temperature was nonsignificant, while the linear term was highly significant. This indicated a constant increase in per cent damage with decreasing temperature. The constants fitted for date showed a highly significant decrease in damage from the first to the fifth week. Within the range of species there were two age-groups, which differed significantly (at the 5\% level). The 3-0 species were more cold resistant than the 2-0 species. The species within each age group did not differ significantly. Interactions between date and species and between date, species and age were found also to be non-significant.

A multiple regression equation was calculated based on all the data. This regression equation calculated an increase of $6.4 \%$ damage for every decrease in temperature of 1 Fahrenheit degree. To show that the observed values corresponded reasonably well with the calculated values, calculated lines and observed values were plotted in Fig. 3. In this figure the calculated lines were plotted only for those weeks in which actual observations were made. It is evident that the frost hardiness increased from the first to the last week of testing. To demonstrate differences in frost hardiness between species and in particular between the 2-0 and 3-0 age groups, calculated regression lines were plotted in Fig. 4 for each species during the second week of testing.

In Fig. 3 the observed data from the preliminary experiments, using 2-2-2 and 2-2-1 white spruce, were plotted. The calculated line for the first week of the 3-0 white spruce fitted these observed values reasonably well.

\section{DiscusSION}

A linear relationship was demonstrated between frost damage and temperature. This relationship was tested only between $13^{\circ}$ and $27^{\circ} \mathrm{F}$. and it may or may not exist outside this tested temperature range. The spread in temperature between first damage and total killing (about 15 Fahrenheit degrees) seems too large and probably reflects the variation in temperature within the freezing chamber. The temperatures which resulted in 50 per cent damage during the second week ranged from $18^{\circ} \mathrm{F}$. for white pine to $24^{\circ} \mathrm{F}$. for larch. These figures indicate the range where damage may be expected.

- Transformation of the data was considered, but rejected because:

a) it was not possible to determine what transformation would satisfy best the assumptions of normality, additivity and homogeneity of variance on the basis of so few data

b) usual transformation such as arc sin are unsatisfactory between $0-10 \%$ and $90-100 \%$ which are the questionable regions on the original scale. 


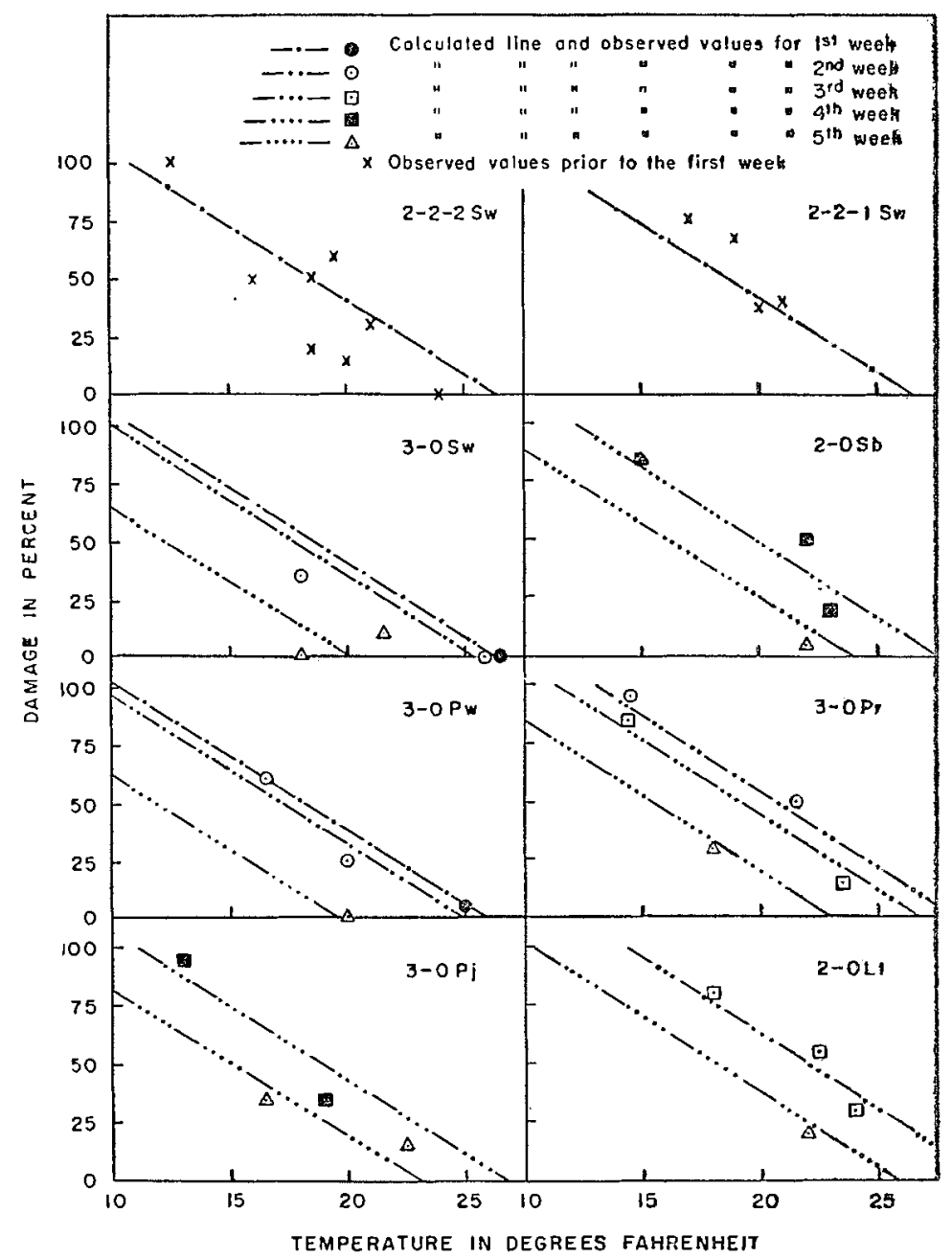

FIGURE 3. Calculated regression lines for all the species tested, which show the relationship between the damage (in per cent) and the average minimum temperature (in degrees Fahrenheic). Calculated lines are only shown for those weeks in which the species were tested. Observed values are plotted to show that small variations existed between calculated and observed values. The calculated 3-0 white spruce line for the first week is plocted with the data of the 2-2-1 and 2-2-2 white spruce. 


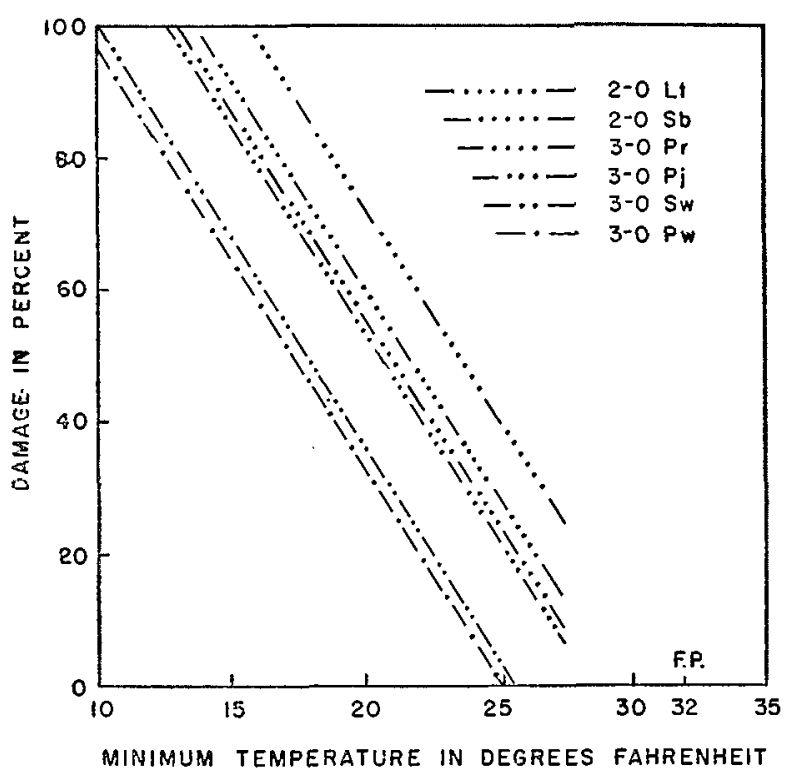

FIGURE 4. Calculated regression lines for all species corresponding to the second week of testing (Aug. 18 - Aug. 25, 1963).

Differences between species probably exist but they were not demonstrated by this experiment. More carefully controlled conditions are required. As expected the most sensitive seedlings were those that were still growing in height, the black spruce and larch.

During the five week period of the experiment (Aug. 11-Sept. 15), a small but noticeable increase in frost hardiness occurred from the first to the fifth week. Such an increase can be expected with the onset of dormancy. Parker (1961) found that during the summer the degree of frost hardiness of certain woody evergreens remained about the same. In agreement with this, the data of the 2-2-1 and 2-2-2 white spruce tested in July were similar to the data of the 3-0 white spruce tested a month later.

The results of this experiment should be considered as a first approximation to the true relationship between the various factors and damage.

\section{ACKNOWLEDGEMENTS}

The authors are grateful to Mrs. S. A. Buckingham, Mr. N. W. McLeod and Mr. A. G. Cameron, all of the Ontario Department of Lands and Forests, for their assistance in the various phases of the work. 


\section{Literature Cited}

BAKER, F. S. 1934. Theory and practice of silviculture. McGraw-Hill Book Co. Inc., New York.

CANADA DEPARTMENT OF FORESTRY, 1963. Annual report of the forest insect and disease survey. Forest Entomology and Pathology Branch, Ottawa, Canada.

DAY, W. R. and T. R. PEACE, 1934. The experimental production and the diagnosis of frost injury on forcst trees. Oxf. For. Mem. 16:1-60.

HOUGH, A. F. 1945. Frost pockets and other microclimates in forests of the Northern Allegheny Plateau, Ecology 26:235-250.

KORSTIAN, C. F. 1921. Effect of a late spring frost upon forest vegetation in the Wasatch mountains of Utah. Ecology 2:47-52.

LI, J. C. R. 1964. Statistical Inference. Vol. II. The multiple regression and its ramifications Edwards Brothers Inc., Ann Arbor, Mich.

PARKER, J. 1961. Seasonal changes in cold resistance of some Northeastern woody evergreens. J. For. 59:108-111.

PAULSELL, L. K. and D. B. LAWRENCE, 1963. Artificial frost apparatus. Ecology 44:146-148.

POMERLEAU, R. and R. G. RAY, 1957. Occurrence and effects of summer frost in a conifer plantation. For. Res. Div., Tech. Note 51, Dept. Northern Affairs \& National Resources, Canada.

STOECKELER, J. H. 1965. Spring frost damage in young forest plantings near La Crosse, Wisconsin. J. For. 63:12-14. 